ORIGINAL ARTICLE

\title{
Diagnosing and treating attentional difficulties: a nationwide survey
}

\section{McKenzie, C Wurr}

See end of article for authors' affiliations ......................

Correspondence to: C Wurr, Cringlebar House, 415 Bradford Road, Leeds LS28 7HQ, UK; kate.wurr@nhs.net

Accepted 4 March 2004
Aims: To ascertain from paediatricians and child psychiatrists their views regarding the aetiology, assessment, and diagnosis of attentional difficulties in children, and the prescribing of stimulant medication for such difficulties.

Methods: Using a questionnaire devised by the authors, 465 paediatricians and 444 child psychiatrists were surveyed.

Results: The overall response rate was $73 \%$. Some $94 \%$ of child psychiatrists and $29 \%$ of paediatricians routinely dealt with attentional difficulties. Views on aetiology, classification, and diagnosis were varied. More than $60 \%$ of both groups were prepared to prescribe stimulant medication without a formal diagnosis being made. Comorbid conduct disorder and the views of other professionals and of parents have an impact on practice.

Conclusions: This survey demonstrates that there is a range of approaches to attentional difficulties by both paediatricians and child psychiatrists. l: nattention, hyperactivity, and impulsivity are commonly reported symptoms in children and provide the basis for a number of diagnoses described in formal classification systems. The expectations and demands on clinicians to make a diagnosis and to prescribe for children with these symptoms have increased in the last decade. However, the validity of such diagnoses and the utility of pharmacological treatments have been the subject of considerable debate in both professional and public arenas. ${ }^{1-2}$

Other related issues should be considered. Both biological and environmental aetiological mechanisms leading to attentional difficulties have been suggested and there is unlikely to be one single causative factor..$^{2-5}$ Various guidelines have been developed as to how assessments should be carried out. An emerging consensus is the importance of collecting information from a number of sources including school, although assessment processes still vary. ${ }^{6-9}$ Comorbidity has been shown to be important when considering treatment options. ${ }^{10}$ The availability of information (especially on the internet) means that parents are more, although not necessarily better, informed, and may have a specific agenda when seeking medical help.

Few large scale studies have been conducted in the UK looking at assessment and treatment, and the two that have been published in the last 5 years did not examine practitioner beliefs underlying their practice. ${ }^{11}{ }^{12}$ The publication of National Institute for Clinical Excellence (NICE) guidelines on the use of methylphenidate ${ }^{13}$ has pushed for greater standardisation although it has been argued that variation in practice needs to be better understood. ${ }^{14}$ Recent community surveys in Australia and the USA suggest a substantial proportion of children taking stimulant medication (SM) do not have a diagnosis of attention deficit/hyperactivity disorder (ADHD). ${ }^{15}$ We conducted a nationwide survey of child psychiatrists and paediatricians in an attempt to establish the current range of views on aetiology, classification, treatment thresholds, and user/referrer expectations.

In this paper, we use the term "attentional difficulties" throughout to encompass the symptoms of inattention, hyperactivity, and impulsivity as well as formal diagnoses made from either the American Psychiatric Association's
Diagnostic and Statistical Manual of Mental Disorders $(D S M)^{16}$ or the World Health Organisation's International Classification of Diseases (ICD). ${ }^{17}$

\section{METHODS}

\section{Participants}

The reference population for this study was all child psychiatrists and all paediatricians in Great Britain and Northern Ireland. Child psychiatrists were identified via the Royal College of Psychiatrists Faculty of Child and Adolescent Psychiatry mailing list $(n=460)$. An equivalent sized group of paediatricians was identified by selecting a one in three sample from a national medical register using computer generated random numbers $(n=490)$. If the questionnaire was returned with information indicating that the addressee had moved away (with no forwarding address), retired, or died, the index subject was excluded from the study.

\section{Instrument}

The questionnaire was designed by the authors to examine professional approaches and attitudes to attentional difficulties using a "forced choice" format with space for free text comments. Four areas were covered, namely aetiology, diagnosis, assessment, and prescribing. Participants were asked to reflect on their usual practice. We piloted the questionnaire using local clinicians and incorporated any feedback into the final version. A preliminary question ascertained if the clinician routinely dealt with attentional difficulties and it was made clear that even if this were not the case, the questionnaire should be returned. The questionnaire is available as a supplemental file from http:// adc.bmjjournals.com/supplemental.

\section{Procedures}

Ethical approval was sought and granted for this study. Questionnaires were sent with a reply paid envelope and a

Abbreviations: ADHD, attention deficit/hyperactivity disorder; DSM, Diagnostic and Statistical Manual of Mental Disorders; ICD, International Classification of Diseases; NICE, National Institute for Clinical Excellence; SM, stimulant medication 
covering letter explaining the purpose of the study. If no reply had been received within 2 months a repeat questionnaire was sent.

\section{Statistical analysis}

This study was essentially descriptive and the statistics used reflect this. Pearson's $\chi^{2}$ analyses were conducted where dependent variables were dichotomous in order to compare the practice of paediatricians and child psychiatrists.

\section{RESULTS}

A total of 665 completed questionnaires were returned: 323/ $465(69 \%)$ from paediatricians and 342/444 (77\%) from child psychiatrists. A further 41 responses indicated that the recipient had either moved away (with no forwarding address provided), retired, or died.

Some 29\% (93/323) of paediatricians who responded indicated that they are routinely involved in the assessment and treatment of children with attentional difficulties, while 94\% (323/342) of child psychiatrists indicated likewise. The following results refer solely to those respondents who routinely manage children with attentional difficulties.

\section{Aetiology and classification}

Most paediatricians (70\%) and child psychiatrists (56\%) consider that both biological and environmental factors contribute to the aetiology of attentional difficulties (table 1). More child psychiatrists than paediatricians think a biological cause is most likely, while very few of either group see environmental aetiology as being of primary importance.

Nearly half of both groups claim to use solely DSM terms such as "ADHD", "ADDH", and "ADD" when describing attentional difficulties in children, while a similar proportion use a mixture of terms taken from different classification systems.

Approximately one third of both groups use DSM criteria to make a diagnosis. ICD criteria are used by half the child psychiatrists but less than a quarter of the paediatricians. More than a quarter of paediatricians do not use a formal classification system as opposed to $4 \%$ of child psychiatrists. Child psychiatrists are significantly more likely than paediatricians to apply diagnostic criteria tightly $(41 \% \vee 13 \%$; $\left.\chi^{2}=25.20 ; \mathrm{p}=<0.01\right)$.

Table 1 Views on aetiology, problem description, and classification systems employed among paediatricians and child psychiatrists

\begin{tabular}{|c|c|c|}
\hline & $\begin{array}{l}\text { Paediatricians } \\
(n=93)\end{array}$ & $\begin{array}{l}\text { Child psychiatrists } \\
(\mathrm{n}=323)\end{array}$ \\
\hline \multicolumn{3}{|l|}{$\begin{array}{l}\text { Aetiology of attentional } \\
\text { difficulties }\end{array}$} \\
\hline Mainly biological & $22(24 \%)$ & $120(37 \%)$ \\
\hline Mainly environmental & $3(3 \%)$ & $13(4 \%)$ \\
\hline Mixture & $65(70 \%)$ & $181(56 \%)$ \\
\hline \multicolumn{3}{|l|}{$\begin{array}{l}\text { How are problems } \\
\text { described? }\end{array}$} \\
\hline Problem list only & $12(13 \%)$ & $13(4 \%)$ \\
\hline DSM label only & $41(44 \%)$ & $140(43 \%)$ \\
\hline ICD label only & $2(2 \%)$ & $22(7 \%)$ \\
\hline Other (including mixture) & $36(39 \%)$ & $146(45 \%)$ \\
\hline \multicolumn{3}{|l|}{ Classification system used } \\
\hline DSM type & 31 (33\%) & $94(29 \%)$ \\
\hline ICD type & $20(22 \%)$ & $162(50 \%)$ \\
\hline No formal system used & $25(27 \%)$ & $12(4 \%)$ \\
\hline Mixture & 11 (12\%) & $53(16 \%)$ \\
\hline \multicolumn{3}{|l|}{$\begin{array}{l}\text { How are diagnostic criteria } \\
\text { applied? }\end{array}$} \\
\hline "Tightly" applied* & $12(13 \%)$ & $136(42 \%)$ \\
\hline
\end{tabular}

Table 2 Assessment procedures used by paediatricians and child psychiatrists

\begin{tabular}{|c|c|c|}
\hline $\begin{array}{l}\text { Routine information } \\
\text { gathered during assessment }\end{array}$ & $\begin{array}{l}\text { Paediatricians } \\
(\mathrm{n}=93)\end{array}$ & $\begin{array}{l}\text { Child psychiatrists } \\
(n=323)\end{array}$ \\
\hline $\begin{array}{l}\text { Phone call/letter from school } \\
\text { Checklist from school } \\
\text { Phone call/letter and/or } \\
\text { checklist from school* } \\
\text { Checklist from parents } \\
\text { Psychometric assessment* } \\
\text { Baseline physical } \\
\text { investigations }\end{array}$ & $\begin{array}{l}66(75 \%) \\
70(79 \%) \\
77(91 \%) \\
68(76 \%) \\
30(36 \%) \\
73(83 \%)\end{array}$ & $\begin{array}{r}264(82 \%) \\
277(86 \%) \\
317(99 \%) \\
277(86 \%) \\
65(20 \%) \\
224(71 \%)\end{array}$ \\
\hline
\end{tabular}

\section{Assessment}

More than $90 \%$ of both groups routinely obtain assessment information from schools, although child psychiatrists are more likely than paediatricians $\left(\chi^{2}=15.62 ; \mathrm{p}<0.01\right)$ to do so (table 2). More than two thirds of each group perform baseline physical investigations. Paediatricians are more likely to collect psychometric testing information $\left(\chi^{2}=9.17\right.$; $\mathrm{p}<0.01$ ).

\section{Use of stimulant medication}

Almost all paediatricians and child psychiatrists indicated that they prescribe SM at least sometimes and the majority are prepared to prescribe on occasion without a diagnosis being made (table 3). More than half the paediatricians and a third of child psychiatrists indicated that their decision to prescribe SM would be affected if both attentional difficulties and conduct disorder were present in children. Most would prescribe less readily although a sizeable minority would prescribe more readily.

\section{Expectations of families and referrers}

Responses from both paediatricians and child psychiatrists showed that parents often had preconceived ideas that their child had ADHD (or similar) (table 4). Furthermore, both groups frequently perceived pressure to prescribe from parents as well as education professionals. Such pressure was less evident from social services, but was more likely to be encountered from this source by child psychiatrists than paediatricians $\left(\chi^{2}=11.39 ; \mathrm{p}<0.01\right)$. Under this perceived

Table 3 Use of stimulant medication (SM) among paediatricians and child psychiatrists

\begin{tabular}{lcc} 
& $\begin{array}{l}\text { Paediatricians } \\
\text { (n=93) }\end{array}$ & $\begin{array}{l}\text { Child psychiatrists } \\
\text { (n=323) }\end{array}$ \\
\hline $\begin{array}{l}\text { How often is SM used for } \\
\text { attentional difficulties? }\end{array}$ & \\
$\begin{array}{l}\text { Often } \\
\text { Sometimes }\end{array}$ & $36(39 \%)$ & $195(60 \%)$ \\
Never & $51(55 \%)$ & $125(39 \%)$ \\
How often is SM used without & $3(3 \%)$ & $3(1 \%)$ \\
a formal diagnosis (for example & \\
ADHD) being present? & $1(1 \%)$ & $2(1 \%)$ \\
Often & $54(58 \%)$ & $194(60 \%)$ \\
Sometimes & $27(29 \%)$ & $122(38 \%)$ \\
Never & $5(5 \%)$ & $4(1 \%)$ \\
Formal diagnoses not used & \\
How would comorbid conduct & & \\
disorder affect likelihood & & $37(11 \%)$ \\
to prescribe SM? & & \\
More likely & $16(17 \%)$ & \\
No difference & $33(35 \%)$ & \\
Less likely & $36(39 \%)$ & \\
\hline & &
\end{tabular}




\begin{tabular}{|c|c|c|}
\hline & $\begin{array}{l}\text { Paediatricians } \\
(\mathrm{n}=93)\end{array}$ & $\begin{array}{l}\text { Child psychiatrists } \\
(n=323)\end{array}$ \\
\hline \multicolumn{3}{|c|}{$\begin{array}{l}\text { How often are parents seen to } \\
\text { have preconceived ideas that } \\
\text { their child has ADHD (or } \\
\text { similar)? }\end{array}$} \\
\hline Offen & $57(61 \%)$ & $187(58 \%)$ \\
\hline Sometimes & $31(33 \%)$ & $131(41 \%)$ \\
\hline \multicolumn{3}{|c|}{$\begin{array}{l}\text { Source of pressure (at least } \\
\text { sometimes) to prescribe SM }\end{array}$} \\
\hline Social services* & $25(28 \%)$ & $155(49 \%)$ \\
\hline Education & 77 (85\%) & $284(88 \%)$ \\
\hline Parents & 91 (99\%) & $318(99 \%)$ \\
\hline \multicolumn{3}{|c|}{$\begin{array}{l}\text { Likelihood of such pressure } \\
\text { influencing decision to } \\
\text { prescribe SM }\end{array}$} \\
\hline More likely & $26(28 \%)$ & $86(27 \%)$ \\
\hline No difference & $60(65 \%)$ & $218(67 \%)$ \\
\hline Less likely & $2(2 \%)$ & $6(2 \%)$ \\
\hline
\end{tabular}

pressure, more than a quarter of both groups were influenced in the direction of prescribing.

\section{DISCUSSION}

This nationwide survey of paediatricians and child psychiatrists looked at their views regarding the aetiology, assessment, and diagnosis of attentional difficulties in children, and the subsequent prescribing of SM. The response rate $(73 \%)$ indicates that the findings are broadly representative. The results show that despite very similar assessment procedures there is variation between practitioners in terms of diagnosis and treatment. The influence of professional background is relatively minor.

The majority of respondents use diagnostic criteria from formal classification systems (ICD, DSM), but by their own admission do not necessarily apply these "tightly". In addition, some use ICD classification systems to make a diagnosis but DSM terminology to describe the condition they have diagnosed. The use of SM is almost universal. A majority of clinicians indicated a willingness to prescribe without a definite diagnosis having been made, although a substantial minority did not. Comorbid conduct disorder may make some clinicians less likely (and others more likely) to prescribe. Furthermore, clinicians may take into account the views of parents and other agencies.

The current NICE guidance on the use of methylphenidate for ADHD states that assessment should be comprehensive, including information from both home and school. Our results indicate that this recommendation is being followed. The guidance also includes prescriptive advice about diagnostic criteria, implying an expectation of precision in their application. In this study, a number of respondents use no formal classificatory system at all, and of those that do, the majority do not apply criteria tightly. Although the guidance recommends that methylphenidate is indicated where a firm diagnosis has been made, it is also possible to prescribe it when this is not the case but where children are "experiencing severe problems due to inattention or hyperactivity/ impulsiveness". We have found that the majority of our respondents do this at least sometimes, suggesting that this is indeed common practice.

Our findings suggest that diagnoses made by one clinician will not necessarily be those that would be made by another despite very similar assessment procedures. The use of DSM and ICD together is likely to lead to even less diagnostic reliability as the two classification systems do not use coterminus criteria. One explanation for this seemingly curious finding may be that while the ICD classification system is most commonly used in this country by professionals, it is DSM terminology that predominates in the media, and that families are most familiar with.

It is good clinical practice to make decisions about the management of any condition collaboratively. In this study, practitioners report that they perceive not only parents, but also social services and education as having an influence on their prescribing practice. This may go some way to explaining the variation in practice this study has highlighted, and is an inherent difficulty in producing categorical guidelines.

The study has some limitations. Questionnaire methodology may not necessarily reflect real practice to the same extent as chart reviews or the use of vignettes. The initial sampling produced two groups of comparable size, although when the clinicians who did not routinely see this group of children were excluded (a previously unknown number), the resulting groups remained of reasonable, but not equivalent, sizes. As nearly all child psychiatrists report seeing children with attentional difficulties, the findings of this study describe child psychiatrists in general. In contrast, only paediatricians who routinely manage attentional difficulties are represented in the findings (although probably this is the group that matters). Some of the differences in the responses between the two professional groups could be explained by referral bias or other possible confounding variables. Referrals made to each may differ, for example child psychiatrists seeing children referred on by paediatricians and paediatricians seeing a younger group in whom hyperactivity is more prominent than inattention. There was no indication from the respondents that the use of the term "attentional difficulties" limited their answers to a particular group of children.

\section{SUMMARY}

This study was designed to investigate professional attitudes (and differing practices) regarding the diagnosis and treatment of attentional difficulties in children. Diagnostic practice varies between clinicians as shown by their use of classification systems and terminology. Treatment thresholds also vary. However, this is not explained by professional background as the differences between paediatricians and child psychiatrists are not marked. Attentional difficulties and their treatment exemplify issues commonly raised in paediatrics and child mental health about the utility of diagnosis, and the relative influences of parents, clinicians, and other agencies on how a child's problems are labelled and treated.

\section{ACKNOWLEDGEMENTS}

The authors are grateful to the clinicians who took part in this study.

\section{ELECTRONIC-DATABASE INFORMATION}

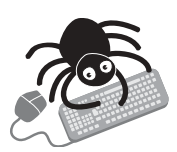

The questionnaire is available as a supplemental file from http://adc.bmijournals.com/supplemental.

\section{Authors' affiliations}

I McKenzie, Glen Acre House Child and Family Service, 21 Acre House Avenue, Lindley, Huddersfield HD3 3BB, UK

C Wurr, Cringlebar House, 415 Bradford Road, Leeds LS28 7HQ, UK 
This research was supported by a project grant from the Association for Child Psychology and Psychiatry.

Conflict of interest: none declared.

\section{REFERENCES}

1 Levy F. Attention deficit hyperactivity disorder. BMJ 1997;315:894-5.

2 Williams C, Wright B, Partridge I. Attention deficit hyperactivity disorder - a review. Br J Gen Pract 1999:49:563-71.

3 Sandberg S. Hyperkinetic or attention deficit disorder. Br J Psychiatry 1996:169:10-7.

4 Taylor E. Syndromes of attention deficit and overactivity. In: Rutter M, Taylor E, Hersov L, eds. Child and adolescent psychiatry. Modern approaches. Oxford: Blackwell Science, 1994:285-307.

5 Cantwell DP. Attention deficit disorder: a review of the past 10 years. J Am Acad Child Adolesc Psychiatry 1996;35(8):978-87.

6 Hill P, Taylor E. An auditable protocol for treating attention deficit/ hyperactivity disorder. Arch Dis Childhood 2001;84:404-9.

7 American Academy of Child and Adolescent Psychiatry. Practice parameters for the treatment of children, adolescents and adults with attention-deficit/ hyperactivity disorder. J Am Acad Child Adolesc Psychiatry 1997;36/suppl 10):85-121.

8 Overmeyer S, Taylor E. Principles of treatment for hyperkinetic disorder: practice approaches in the UK. J Child Psychol Psychiatry 1999;40:1147-57.
9 British Psychological Society. Attention deficit hyperactivity disorder (ADHD). A psychological response to an evolving concept. Leicester: The British Psychological Society, 1996.

10 MTA Co-operative Group. Moderators and mediators of treatment response for children with attention-deficit/hyperactivity disorder: the multi-modal treatment study of children with attention-deficit/hyperactivity disorder. Arch Gen Psychiatry 1999;56:1088-96.

11 Bramble D. Psychostimulants and British child psychiatrists. Child Psychol Psychiatr Rev 1997;2:159-62.

12 Salmon G, Kemp A. ADHD: a survey of psychiatric and paediatric practice. Child Adolesc Mental Health 2002;7:73-8.

13 National Institute for Clinical Excellence. Technology appraisal guidance 13: guidance on the use of methylphenidate (Ritalin, Equasym) for attention deficit/hyperactivity disorder (ADHD) in childhood. London: NICE, 2000

14 Gilbody S, House A. Variations in psychiatric practice. Neither unacceptable nor unavoidable, only under-researched. Br J Psychiatry 1999; 175:303-5.

15 Rey JM, Sawyer MG. Are psychostimulant drugs being used appropriately to treat child and adolescent disorders? Br J Psychiatry 2003;182:284-6.

16 American Psychiatric Association. Diagnostic and statistical manual of mental disorders, 4th ed. Washington, DC: APA, 1994.

17 World Health Organisation. The ICD-10 classification of mental and behavioural disorders: diagnostic criteria for research. Geneva: World Health Organisation, 1993.

ARCHIVIST.

\section{Bronchiectasis in patients without cystic fibrosis}

n prosperous countries most children with bronchiectasis have cystic fibrosis and the condition is otherwise uncommon. In economically disadvantaged countries it remains an important feature of chronic suppurative lung disease. In the UK the number of children admitted to hospital with bronchiectasis has declined in the last 50 years, probably because of improved overall health and nutrition and vaccination against whooping cough and measles. For diagnosis high resolution computed tomography (HRCT) has replaced bronchography. Despite the decline almost $10 \%$ of the children referred to the paediatric respiratory unit in Newcastle upon Tyne between November 1996 and May 2002 had noncystic-fibrosis bronchiectasis confirmed by HRCT (KM Eastham and colleagues. Thorax 2004; 59:324-7). Workers there have reviewed their findings in these 93 patients.

The HRCT diagnosis was based on one or more of the following four findings: cross sectional diameter of at least one bronchus greater than that of the accompanying pulmonary artery, mucoid impaction within a dilated bronchus, bronchi non-tapering in longitudinal cuts, and bronchi visible adjacent to non-mediastinal pleura. The 93 children were aged up to 16 years (median 1.1 years) at the onset of symptoms and two thirds were boys. The age at HRCT diagnosis was $1.6-18.8$ years (median 7.2 years) and the time from symptom onset to diagnosis was $0.2-14.8$ years (median 3.0 years). Most bronchiectasis was postpneumonic ( 28 cases, $30 \%)$; 19 cases $(21 \%)$ were associated with immunodeficiency or immunosuppression, and 17 (18\%) were idiopathic. Among the immunoincompetent group four children had chronic grandomatous disease and one agammaglobulinaemia; five had had heart transplants and one had been treated for leukaemia. Deficiencies of $\operatorname{IgA} \operatorname{Ig} G_{2}$, $\mathrm{IgG}_{3}$, or specific antibodies were demonstrated in a number of children. Other conditions associated with bronchiectasis included bronchiolitis obliterans (8 cases), congenital lung abnormality (4), and chronic aspiration (3). Almost half of the children (45) had a referral diagnosis of asthma, erroneous in 39 cases. The organisms most commonly isolated from the 93 children were Haemophilus influenzae, Streptococcus pneumoniae, and Moraxella catharalis. Eighty-one children had had a chest X-ray in the 12 months before the HRCT diagnosis but only five reports accurately predicted the HRCT findings. Repeat HRCT scanning was done for 18 children 18 months to 5 years after the diagnostic scan; in six cases there had been complete resolution of the bronchiectasis, six had remained the same, five had progressed, and in one case there had been improvement but not complete resolution.

Some children with a diagnosis of "cough variant asthma" may have bronchiectasis. Chest X-ray is unreliable in the diagnosis. Treatment with antibiotics and physiotherapy may be curative for disease with a non-progressive or idiopathic aetiology. The prevalence of bronchiectasis in this population is estimated at around one in 5800 children under 17 years. To take account of the possibility of resolution the authors of this report propose the terms prebronchiectasis, HRCT bronchiectasis, and established bronchiectasis. 